Ernst Troeltsch

Kritische Gesamtausgabe 


\section{Ernst Troeltsch \\ Kritische Gesamtausgabe}

im Auftrag der Kommission für Theologiegeschichtsforschung der Bayerischen Akademie der Wissenschaften herausgegeben von

Friedrich Wilhelm Graf · Gangolf Hübinger

Band 22

De Gruyter 


\title{
Ernst Troeltsch
}

\author{
Briefe V \\ (1918-1923)
}

\author{
herausgegeben von \\ Friedrich Wilhelm Graf \\ in Zusammenarbeit mit \\ Harald Haury
}

De Gruyter 
Die Troeltsch-Edition wird als Vorhaben der Bayerischen Akademie der Wissenschaften (Kommission für Theologiegeschichtsforschung) im Rahmen des Akademienprogramms von der Bundesrepublik Deutschland und vom Freistaat Bayern gefördert.

ISBN 978-3-11-067741-6 e-ISBN (PDF) 978-3-11-068168-0

Library of Congress Control Number: 2013044525

Bibliografische Information der Deutschen Nationalbibliothek.

Die Deutsche Nationalbibliothek verzeichnet diese Publikation in der Deutschen Nationalbibliografie; detaillierte bibliografische Daten sind im Internet über http://dnb.dnb.de abrufbar.

(C) 2020 Walter de Gruyter GmbH, Berlin/Boston Schutzumschlag: Rainer Engel, Berlin Satztechnik ( $\left.{ }^{A} \mathrm{~T}_{\mathrm{E}} \mathrm{X}\right)$ : David Kastrup, Waltrop Satz: Hannelore Loidl-Emberger, St. Wolfgang und Johannes Heider, München Druck und Bindung: Hubert \& Co. GmbH \& Co. KG, Göttingen 